\title{
16
}

\section{Are They Really Teachers? Problem-Based Learning and Information Professionals}

\author{
Michael Anderson \\ Virginia Baldwin \\ University of Nebraska, Lincoln
}

Traditionally, working with teaching faculty is the primary consulting role for most faculty development professionals. The boundaries, however, are not always clear regarding instructional assistance that is provided to other personnel. This chapter demonstrates how collaboration among faculty consultants and information specialists can result in enhanced library utilization and better research-related instruction. Our model uses problem-based learning (PBL) as a vehicle for teaching research and retrieval skills in either a single class experience or in multiple classroom visits with an enginecring librarian.

\section{INTRODUCTION}

Traditionally, working with teaching faculty is the primary consulting role 1 for faculty development professionals. However, the boundaries are not always clear regarding instructional assistance given to other personnel such as those who provide information services. Does the scope of faculty development include the providing of service to nonteaching faculty or to those who teach infrequently? Searching relevant literature provided some guidance about faculty development roles but the definitions are, perhaps necessarily, general. For example, in Morrison (1997), we found the following: "faculty developers provide consultative assistance to faculty members and teaching assistants in such varied domains as research, scholarly writing, and career planning" (p. 122). Is an engineering librarian, generally not considered teaching 
faculty, who instructs single sessions about the utilization of a technical library and multiple databases really teaching? Moreover, is working with an information specialist within the domain of faculty consulting? In short, are they really teachers and how should an instructional consultant address the needs of nonteaching faculty?

This chapter describes the collaboration between a faculty teaching consultant and an engineering librarian. The librarian is a new faculty member who made initial contact with the teaching and learning center after the annual new faculty orientation. The center participates in the orientation and shares information about services supportive of faculty teaching efforts. Our initial contact concerned short-term (one or two class sessions) teaching assignments where teaching about engineering library utilization was the curriculum. Initially, we discussed teaching tactics and strategies for designing courses as any consultant and client would. However, the fact that the course under consideration was, historically, a single session taught in each of several engineering courses about conducting library research, seemed to stretch the consulting boundaries. The result was a mutually beneficial experience regarding the impact of informed pedagogy, specifically problem-based learning (PBL), on nontraditional instructional settings. The librarian requested information on innovative practices that could enhance the more traditional instructional methods that she used at a previous institution. She felt that the old methods were ineffective and sought a method that was more motivational for students. During our consultation process, we developed a set of general teaching questions about library research instruction: What are the objectives for the instruction sessions? How will our methodological choices help students accomplish the objectives? How will we know if the students learn the requisite skills? If it is correct that learning that happens in the natural setting is more authentic (Brown, Collins, \& Duguid, 1989; Lave, 1988; Vygotsky, 1986), then how can one or two classroom visits, with the intent of teaching about engineering research strategies, best emulate the library research environment?

\section{The Objective}

Graduates of university engineering programs in today's information age will find continuing education and research a necessity. Engincers will need to use information resources when solving design problems and for tracking new discoveries and ideas that are developed by other engineers and scientists. The Accreditation Board for Engineering and Technology (ABET) recognizes this and requires cvery engineering curriculum to include a lifelong learning com- 
ponent (Engineering Accreditation Commission, 1995). For civil engineering, which is one of the mainstream engineering fields, lifelong individual learning is considered the core issue (Grigg, 1998). With this in mind, we discussed the objectives for the engineering library session extensively, paying particular attention to the fact that students would receive limited exposure to the material. Moreover, if the primary objective is for the students to be able to apply what they have learned in their current or future engineering coursework, then we should not become bogged down with a laundry list of topics. McKeachie (1994) advises the same, saying that objectives should not cover a certain set of topics, but learning that can be applied and used in situations outside the course. Our overarching objective is for students to be able to construct a research query and conduct a complex library search for engineering information that is useful both in the classroom and for lifelong learning.

Once this objective was established, the challenge was designing a ses$\operatorname{sion}(\mathrm{s})$ that incorporated the necessary content databases and information formats while, at the same time, helped the students learn to use and apply the research process. We know that in courses where both content and process are valuable, the principles of problem-based learning are often used to organize the curriculum. So, why not pose actual problems used by engineering professors to more closely emulate classroom objectives and career objectives? We believe that this method more closely reflected the real work of engineers.

\section{The MeThOD}

Engineering education literature stresses teaching techniques that address various student learning styles. Maskell and Grabau (1998) stress the importance of problem-based cooperative learning and conclude that this mode provides an environment that builds students' motivation and morale. The result is a better attitude toward learning that enhances students' sense of achievement associated with completion of the project. Further, Bakos (1997) directly ties the lifelong learning component to web-based Internet resources and the ability of the engineering student/practitioner to access and critically evaluate them. He refers specifically to the multitude of government agencies that are organizing and posting information that has potential use in the field of civil engineering. Bakos (1997) also gives examples of freely available information from other sources, namely research results and specialized collections from universities and libraries. The use of problem-based learning for library instruction accommodates learning styles and mimics the process of continued learning. 
A general principle supporting $\mathrm{PBL}$ is that learning is initiated by posing problems that the students want to solve (Boud \& Feletti, 1991). While we know that solving library-based problems may not be highly motivating to undergraduate engineering students, we believe when faced with the alternative (a lengthy lecture on how you might use an engineering library), posing actual problems will produce more energetic and authentic student responses. Another PBL principle, cooperative learning, suggests that students find better solutions when they collaborate and will be better prepared for the workforce if they can work with others (Duch, Allen, \& White, 2000). Our idea was that when students work together on real engineering questions the result will be a more thorough understanding of engineering library resource utilization. Exposure to PBL literature provided by the teaching consultant and attendance at PBL related workshops helped to convince the librarian that this method would be more effective than traditional approaches.

Good problems require students to make decisions based on facts, information, logic, and/or rationalization. Problems should require that students define what assumptions are needed, what information is relevant, and what steps or procedures are required to solve the problem. (Duch, Allen, \& White, 2000, p. 1)

For example, a student may pose the simple question, "What are the different designs for mobile phones?" Knowing how to separate relevant information from less important data may not be as difficult as in the case of a more complex question such as, "What are the design characteristics of a model web search engine interface?" In both questions, the student will need experience at narrowing the search to find salient information, but in the latter question, many more complex decisions are needed. Posing a problem that students will have to solve and discuss, as in our model, during a second session with the librarian, is active and experiential. Further, this assignment allows the librarian an opportunity to track student success and field questions about barriers (learning issues) that arose during the research process.

\section{The Model.}

We believe that students, while perhaps Internet savvy, are not as disposed to identifying accuracy in nonlibrary sources; moreover, many students do not know what scholarly journals are or how to use them. As a practicing engineer, in keeping with a lifelong learning mission, these resources will be important on an ongoing basis. Some of these resources are available freely over the In- 
ternet. Advanced methods that can be used to more precisely search the Internet, when learned as concepts, can be applied equally to periodical indexes and are transferable from one index to another. In addition to learning these concepts and how to use them, students will need some tools for evaluating the information. These tools will enable them to distinguish web site information sources from published sources, scholarly resources from nonscholarly resources, and more highly researched and accepted information sources from those less researched.

Our model uses a two-session format in which the librarian visits classes for the purpose of instruction about engineering research and library utilization specific to that course. During the first session, the librarian introduces a sample problem, based on those developed by engineering professors, and a flowchart (Figure 16.1) that outlines the basic types of information sources, categorizes the sources, and indicates source reliability (Flow of Scientific Information, n.d.). In addition, students are introduced to the database web sites so as to familiarize them with specific database interface structures that they will use when they search in groups. And finally, students are given a resource utilization assignment.

For each class, we consulted in advance with teaching faculty about possible topics that are typical either for a research project, thesis, dissertation, or a topic of professional interest, depending upon course content and level. Six topics were identified for each class. The topics were listed on the assignment and the students were given a choice of the six topics. Once the topic was selected, the next task was to formulate a research question associated with a specific research task that requires the students to identify relevant information sources. The following are examples of research questions and the keywords actually used in student searches in two engineering classes:

- Mechanical Engineering

Topic: Liquid fueled rocket engines

Research Question: (What has been published about liquid) "rocket fuel efficiency and performance?"

Keywords Used: Liquid fuel rocket, efficiency, and performance

- Construction Management

Topic: Concrete admixtures

Research Question: "I would like to find out what amounts of the different aggregates makes concrete the strongest."

Keywords Used: Concrete, admixtures, strength 


\section{Figure 16.1}

Flow of Scientific Information

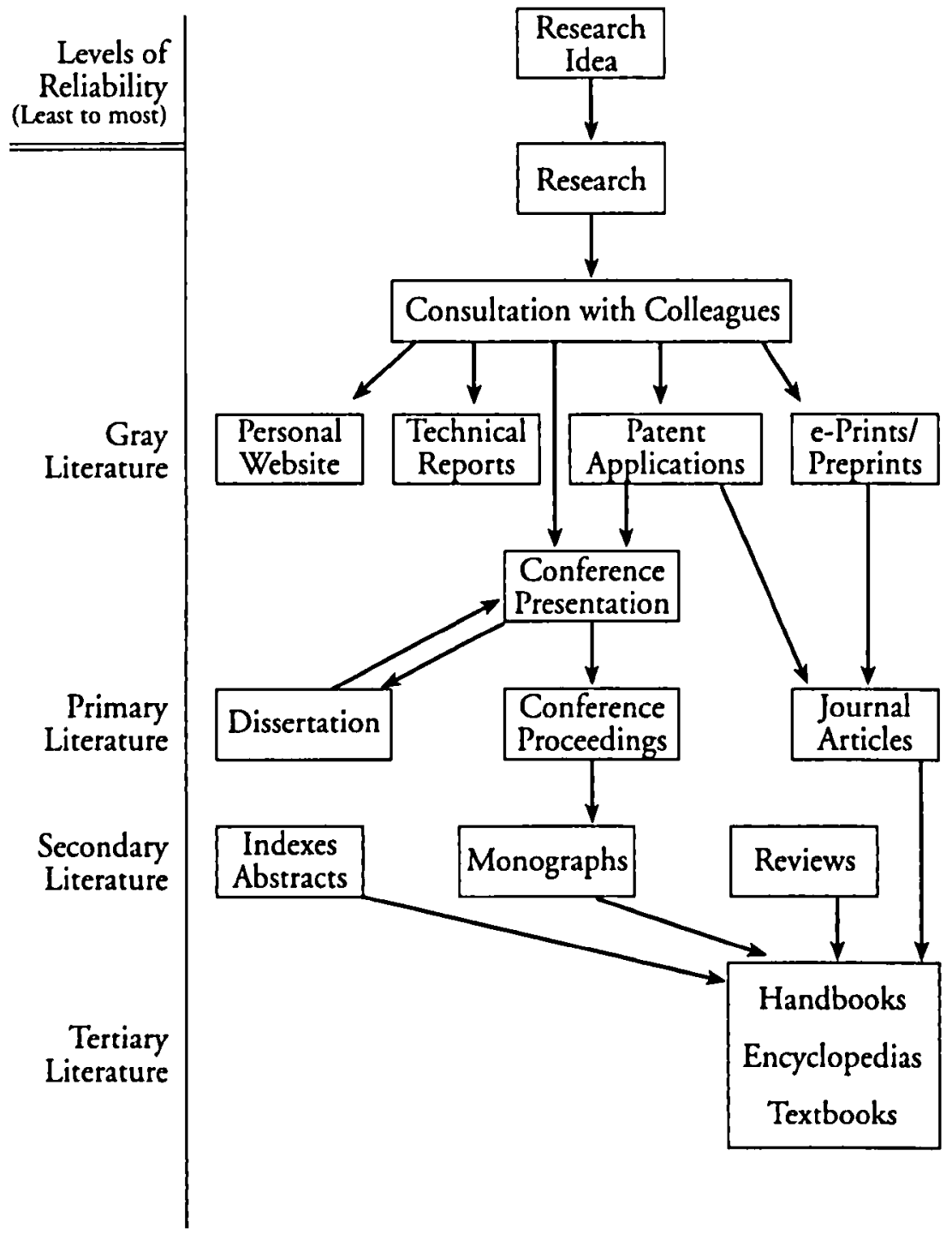


Students then select (or are assigned) partners. In these small groups they will be expected to research their query and report the details of their search. Group members must visit the library facilities, physically examine print journals, and use pertinent online sources to gather information. Each group is expected to record the steps taken to either narrow or broaden a search and the search terms they used. They must also explain how they determined the reliability of the information they gathered. The assignment questions are representative of the categories shown in Figure 16.1, such as technical reports and patent information (gray literature), conference proceedings and journal articles (primary literature), and reference resources (tertiary literature). Secondary sources such as periodical indexes, used to find a citation in a specific journal and issue, are introduced as tools to facilitate access to the primary literature (Solla, 2000). Questions are included that require student evaluation of information sources using criteria learned through actual examination of issues of two journals selected by the librarians/instructor. Figure 16.2 represents an example of a decision-making guide meant to show the reader how students might conduct their search assignment.

The goal of the second session is to use student search results to enhance instruction. Students discuss their searches, share the barriers that prevented successful searches, and exchange strategies and tactics that were helpful in completing the assignment. The library specialist uses student examples to reemphasize the key concepts, clarify learning objectives, and teach to issues left unresolved by student searches. The librarian can extend the learning process by inviting students or entire groups to the engineering library for more in-depth instruction or to solve specific problems that arose during the exercise.

A one-session model was also developed because some engineering professors will not commit more than one class day to library instruction. In the single session model, the librarian emphasizes the value of research skills to student coursework and future careers, provides instructions about completing the assignment, and introduces the mechanics and fundamental concepts involved in completing it. The searches are completed cooperatively in small groups and submitted to the course professor the following week for grading by the librarian and library staff. The limitations of a single session are mitigated when written feedback about the assignment is included. In the single session, students are afforded the same opportunity for personal assistance in the engineering library, again, to enhance the students' ability to learn the research process. 


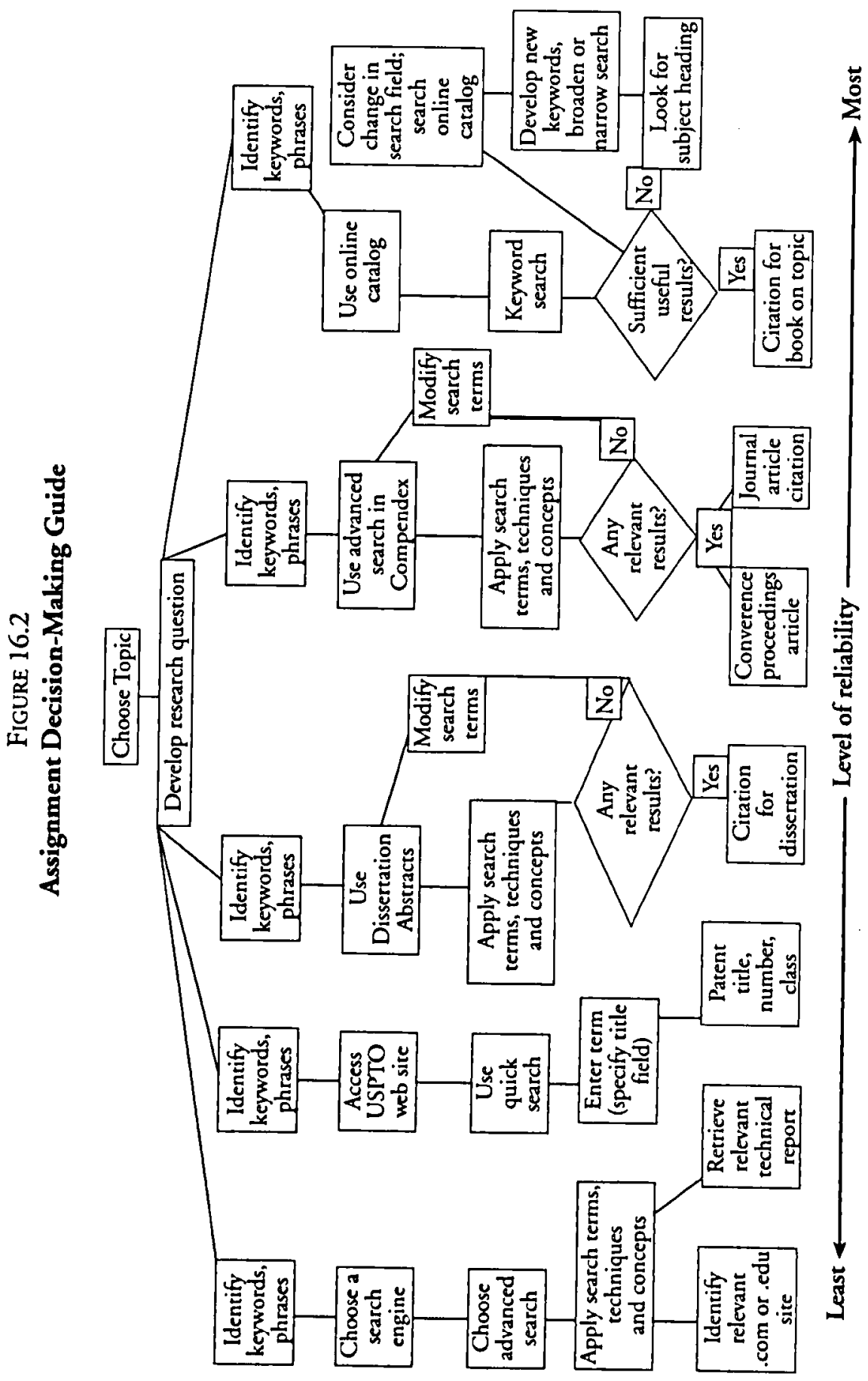




\section{The Results}

Teaching that accomplishes learning objectives is desirable in any form of instruction but it is more difficult when class time is limited. The constraint of posing library research problems within two class sessions means that assessing student work must be part of the instruction. Often, assessment is designed as a summative apparatus rather than formative, but in this model, the second session utilizes assessment for learning rather than assessment of learning (Stiggins, 2001). The completion of the assignment does provide a limited evaluation of the learning and, more important, the projects create a focus for student discussion and are used as a teaching device in the second session. During the second session, students are asked conceptual questions such as, "What are some of the techniques that you used on your assignment to narrow your search or to make it more precise?" After sufficient prompting in some classes, several students responded based on how they completed the assignment by citing a variety of methods, such as adding a term with the Boolean operator "and" or searching in a more restricted field such as title or subject. Students are encouraged to notice the transferability of this knowledge from one engineering topic to another and to other search engines and databases.

In addition, a one-minute evaluation was administered that included writing a sentence describing any new concepts that were learned. The results indicated that many students felt more comfortable with using periodical indexes, recognized their usefulness, and learned how to evaluate information sources. A second question asked students to write a sentence describing something that is still unclear. Results provided additional ideas for future sessions. The one-minute evaluation included responses regarding the usefulness of this knowledge during their educational and professional careers. The responses indicated that students did expand their information gathering techniques and found the experience and knowledge gained to be useful. See the appendices for the complete results for one engineering class.

\section{Conclusion}

The benefits of the consultation process and our collaboration extend beyond the development of a successful PBL teaching model for engineering library instruction. The engineering students and professors involved provided positive feedback about the changes and the impact on learning; however, other secondary effects may be just as significant as improved student research skills. For example, our collaboration helped a newly hired engineering librarian 
make connections with other engineering faculty who were impressed with faculty comments about the research skills lessons. The PBL library assignment is now included in more of the College of Engineering and Technology courses. In addition, other engineering faculty members who were trying to implement a problem-based approach in their courses have asked for library support and collaboration.

Another benefit of our partnership is a broader shared understanding of the role of faculty development. For a faculty consultant, making connections with an information specialist is helpful in understanding the role of the librarian as a part of the overall education experience. Our university is a land grant institution, a research level one institution, and an Association of American Universities institution, and as such, has dual missions: One goal is teaching and another is maintaining a commitment to a high research standard. With this in mind, library and information specialists could be considered integral with respect to achieving both goals. Librarians have the ability and impetus to categorize information sources, and a librarian working with a faculty consultant can develop methods that will use these organizational skills more effectively to improve student learning.

\section{REFERENCES}

Bakos, J. D., Jr. (1997). Communication skills for the 21 st century. Journal of Professional Issues in Engineering Education and Practice, 123 (1), 14-16.

Boud, D., \& Feletti, G. (1991). Introduction. In D. Boud \& G. Feletti (Eds.), The challenge of problem-based learning (p. 12). New York, NY: St. Martin's Press.

Brown, J. S., Collins, A., \& Duguid, P. (1989). Situated cognition and the culture of learning. Educational Researcher, 13, 32-41.

Duch, B. J., Allen, D. E., \& White, H. B. (2000, October). Problem-based learning: Preparing students in the 21 st century. In Teaching at UNL, 22(2). The newsletter of the UNL Teaching and Learning Center. Used with permission of Teaching Excellence, a service of POD member services.

Engineering Accreditation Commission of the Accreditation Board for Engineering and Technology (ABET). (1995). ABET engineering criteria 2000. Baltimore, MD: Author.

Flow of Scientific Information. (n.d.). Retrieved December 12, 2001, from http:// www.lib.uwaterloo.ca/usered/grad/researchskills/flow_of_info.htm

Grigg, N. S. (1998). Universities and professional associations: Partnerships for civil engineering careers. Journal of Management in Engineering, 14 (2), 45-55. 
Lave, J. (1988). Cognition in practice: Mind, mathematics and culture in everyday life. New York, NY: Cambridge University Press.

Maskell, D. L., \& Grabau, P. J. (1998). A multidisciplinary cooperative problembased learning approach to embedded systems design. IEEE Transactions on Education, 41(2), 101-103.

McKeachie, W. J. (1994). Teaching tips (9th ed.). Lexington, MA: D. C. Heath.

Morrison, D. E. (1997). Overview of instructional consultation in North America. In K. T. Brinko \& R. J. Menges (Eds.), Practically speaking: A sourcebook for instructional consultants in higher education (pp. 121-129). Stillwater, OK: New Forums Press.

Solla, L. (2000). Chem 602: Lecture, week one. Retrieved December 10, 2001, from http://www.library.cornell.edu/psl/chem602/lectures/lecturel.htm

Stiggins, R. (2001, November 8). Assessment and state performance standards. Workshop presented by the Nebraska State Department of Education, University of Nebraska, Lincoln.

Vygotsky, L. (1986). Thought and language. Cambridge, MA: MIT Press.

Contact:

Michael Anderson

115 Benton Hall

University of Nebraska, Lincoln

Lincoln, NE 68588

Voice (402) 472-9766

Email manderston6@unl.edu

Virginia Baldwin

Associate Professor

Engineering Library

W204 Nebraska Hall

University of Nebraska, Lincoln

Lincoln, NE 68588-0516

Voice (402) 472-3412

Fax (402) 472-0663

Email vbaldwin2@unl.edu

Michael Anderson is a Faculty Instructional Consultant for the University of Nebraska, Lincoln Teaching and Learning Center. The center is the second oldest in the United States and is currently being disbanded for budgetary reasons after 32 years of service to the faculty. Dr. Anderson has been with the center for three years. 
Virginia Baldwin joined the faculty of the University Libraries at the University of Nebraska, Lincoln as Associate Professor and Head of the Engineering Library on Seprember 1, 2000. On September 1, 2001, she was also appointed Head of the Physics Library. Ms. Baldwin is a member of the American Society for Information Science and the American Society for Engineering Education. She is also the Editor of the journal Science and Technology Libraries. 


\section{APPENDIX 16.1}

\section{LibRARY INSTRUCTIONS SESSIONS}

Write a sentence describing one new concept that you learned in these sessions.

\begin{tabular}{ll}
\hline Response & Number \\
\hline How to broaden and narrow searches & 3 \\
\hline How to use Compendex & 7 \\
\hline The variety of available resources & 3 \\
\hline How to search for tech reports & 1 \\
\hline Nothing & 3 \\
\hline Truncarion & 3 \\
\hline How to find periodicals & 3 \\
\hline How to use the UNL Libraries and the Eng. Library & 7 \\
\hline Available Internet resources & 3 \\
\hline How to do patent searches & 2 \\
\hline How to use Boolean logic in searches & 3 \\
\hline How to use Academic Search Elite & 1 \\
\hline Techniques in slowing steel corrosion & 1 \\
\hline
\end{tabular}




\section{APPENDIX 16.2}

Write a sentence describing something that was presented in these sessions that is still unclear to you.

\begin{tabular}{ll}
\hline Response & Number \\
\hline Abstracts & 1 \\
\hline Use of the UNL catalog & 1 \\
\hline Truncation & 3 \\
\hline Nothing & 13 \\
\hline Differences between scholarly and nonscholarly resources & 1 \\
\hline Use of Academic Search Elite & 5 \\
\hline Use of Compendex & 2 \\
\hline How to find journal articles & 1 \\
\hline How to find reference books & 2 \\
\hline How to use the UNL web site & 2 \\
\hline How to use advanced search features & 3 \\
\hline The setup of the library & 2 \\
\hline How to do patent searches & 1 \\
\hline
\end{tabular}




\section{APPENDIX 16.3}

What is your perception of the value of these exercises:

a. In your coursework at UNL

\begin{tabular}{lc}
\hline Response & Number \\
\hline Will be useful in research and assignments & 30 \\
\hline Came too late in my student career & 1 \\
\hline Unsure & 3 \\
\hline It will be of some use & 5 \\
\hline
\end{tabular}

b. In your professional career

\begin{tabular}{lc}
\hline Response & Number \\
\hline Unsure & 6 \\
\hline It should be helpful & 17 \\
\hline It will help me keep up to date on technology & 9 \\
\hline It will help to show what journals professionals use & 1 \\
\hline It will be little or no help & 7 \\
\hline
\end{tabular}

